\section{Failure of Vacuum Insulation at Low Field Strengths}

Pre-BREAKDOWN currents in vacuum-insulated systems are usually regarded as due to field emission. If the electrodes are not subjected to heat treatment, however, these currents occur at unexpectedly low field strengths. We have recently examined a form of conduction at 10-150 kV. D.C. across gaps of a few centimetres in continuously evacuated systems. The current is in this case distinct from field emission because (i) it is critically dependent on anode conditions, and (ii) the voltage required is only slightly changed by large variations in gap-length. Other characteristics of interest are that the current is selfextinguishing, after a charge of the order of microcoulombs has crossed the gap, with only slight drop in voltage; and that the voltage required may be increased by factors up to 2 by increasing the pressure of residual gas in the system.

The mechanism of the conduction is still being investigated; but it is clear that there is a resemblance to the "electron loading' experienced in accelerating tubes in the megavolt field. It is hoped to publish a detailed report shortly.

We wish to thank the Director of the Atomic Energy Research Establishment, Harwell, and the Ministry of Supply for supporting the work and for permission to publish the results.

\section{S. CLIFFORD}

R. L. Fortescue

Queen Mary College, Mile End Road, London, E.1.

J. ROBERTS

Atomic Energy Research Establishment, Dideot, Harwell, Berks.

\section{Definition of Chromatography}

THE belief that the word 'chromatography' was coined by Tswett ${ }^{1}$ about 1906 is incorrect ; it appears to have been widely used, though with a different connotation, for more than a century and a half previously. As so often happens, T'swett appears merely to have adopted an existing word and given it an additional meaning. Paradoxically, many modern works of reference define chromatography in every way but the one which would first spring to the mind of a chemist.

In 1731 , Bailey ${ }^{2}$ defined chromatography as a treatise on colour; in 1835, Field published a book entitled "Chromatography"'. As recently as 1949, Funk and Wagnall" defined chromatography in the same sense and used 'chromatograph' to denote an instrument employed to produce different colours by rotation of a parti-coloured disk. In 1860, Holmes used 'chromatograph' as a verb meaning to represent in colour ${ }^{3}$.

Tswett probably derived 'chromatography', and the allied 'chromatographic' and 'chromatogram', through the word 'chromatology' used by Sorby ${ }^{5}$, with whose work on the differential partition of pigments he was certainly familiar, as he quotes it. Zechmeister and Cholnoky ${ }^{8}$ later characterized 'Tswett's principal separation process exclusively as 'chromatographic adsorption analysis', but, as Koslltoyants and Kalmykov ${ }^{7}$ have recently pointed out, Tswett recognized the possibility of applying his technique more widely than by merely forming coloured zones in simple adsorption columns.

So many processes are now by common consent accepted as forms of chromatography that an unequivocal definition of the word in its present chemical sense presents difficulties. We have proposed the following. "By chromatography is meant those processes which allow the resolution of mixtures by effecting separation of some or all of their components in concentration-zones on or in phases different from those in which they are originally present, irrespective of the nature of the force or forces causing the substances to move from one phase to another'"8,9. This definition embraces not only the various forms of chromatography hitherto achieved but also all forms which have been postulated as theoretical possibilities.

19 Woodstock Close, Oxford.

TREVOR I. WILLIAMS

17 Provost Road, London, N.W.3.

Herbert WeIx

1 Tswett, M. S., Ber. Deut. Bot. Ges., 24, 316(1906); ibid., 384; "Works of the Warsaw Society of Natural Sciences", 14, Riol. Sec., Min. 6 (1903).

2 Bailey, N., "Universal Etymological English Dictionary", 2nd ed. (1731)., "

3 "A New English Dictionary on Historical Principles", 2394 (Edited by Murray, J. S. H., 1893).

"New 'Standard' Dictionary of the English Language" (Funk and Wagnall, New York and London, 1949).

${ }^{5}$ Sorby, H. C., Proc. Roy. Soc., 21, 442 (1873).

"Zechmeister, I., and Cholnoky, L., "Principles and Practice of Chromatography" (English translation) (1941).

"Koshtoyants, K. S., and Kalmykov, K. F.. Biochemistry (Acad. Sci., U.S.S.R.), 16, Min. No. 5 (195i).

${ }^{8}$ Weil, H., and Williams, T. Y., Naturwiss. (in the press).

- Williams, T. I., and Weil, H., Arkiv. för Kemi, Mineralogi och Geologie (in the press).

\section{Zoological Nomenclature}

As from January 23, 1953, the International Commission on Zoological Nomenclature will start to vote on the following cases involving the possible use of its plenary powers for the purposes specified in brackets against each entry. Full particulars of these cases were published on July 23,1952 , in the Bulletin of Zoological Nomenclature, those relating to cases (1) to (4) in Part 8 and those relating to cases (5) to (10) in Part 9 of Vol. 6. (1) Ancylus Müller, 1774 (Cl. Gastropoda) (designation of type species); (2) atrox Baird and Girard, 1853, Crotalus (Cl. Reptilia, Ord. Squamata) (validation); (3) polysticta Cope, 1865, Caudisona (Cl. Reptilia, Ord. Squamata) (validation); (4) Paloeopsylla Wagner, 1903 (Cl. Insecta, Ord. Siphonaptera) (designation of type species); (5) Heterandria Agassiz, 1853 (Cl. Osteichthyes) (designation of type species) ; (6) Lobacantha Kirby, 1837 (Cl. Insecta, Ord. Coleoptera) (suppression, to validate Platypria Guérin, 1840); (7) tereticauda Eschscholtz, 1833, Triton (Cl. Amphibia) (suppression, to validate lugubris Hallowell, 1849, Salamandra) ; (8) Euryrhynchus Miers, 1877 (Cl. Crustacea, Ord. Decapoda) (validation); (9) Pontonia Latreille, 1829 (Cl. Crustacea, Ord. Decapoda) (designation of type species); (10) Martyn, 1784, Universal Conchologist (Ph. Mollusca) (validation of following trivial names published in: arabicum; canaliculus; crenata; denticulata; granosus; haustrum ; heliotropum ; iris ; linea ; maculosum; opalus; papulosum; punctulatus ; purpurata ; smaragdus; sulcatus ; tigris ; vermis).

Comments on the above cases should be sent to me as soon as possible.

Francis Hemming (Secretary to the Commission on Zoological Nomenclature)

28 Park Village East,

Regent's Park, London, N.W.1. 